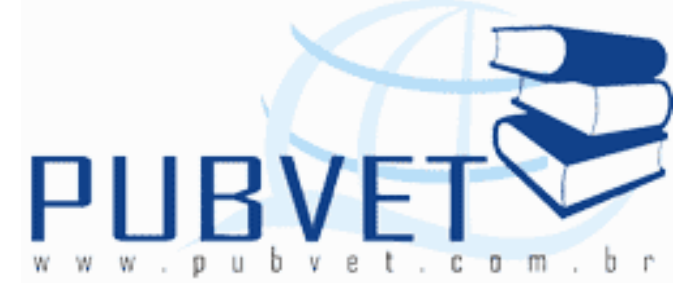

PUBVET, Publicações em Medicina Veterinária e Zootecnia.

\title{
A influência da co-evolução bovinos/carrapatos nos métodos de controle e ambiência na bovinocultura
}

Pedro Gilberto Silva de Morais $^{1}$, Marina Cruvinel Assunção Silva ${ }^{1 *}$, Mayara Fabiane Gonçalves ${ }^{1}$, Alexandre Ambrósio ${ }^{1}$, Nadia Simarro Fagundes², Mara Regina Bueno de Mattos Nascimento 3

${ }^{1}$ Mestrandos do Programa de Pós Graduação em Ciências Veterinárias- UFU.

2 Doutoranda do Programa de Pós Graduação em Ciências Veterinárias- UFU.

3 Professora Doutora do Programa de Pós Graduação em Ciências VeterináriasUFU.

* marinacruvinel@hotmail.com

\section{Resumo}

A bovinocultura é muito desenvolvida no Brasil, mas os ectoparasitas, principalmente os carrapatos, aumentam o custo de produção e dificultam a atividade. No Brasil os bovinos são exóticos, e quando importados trouxeram também seus parasitos. Para controle do ácaro várias técnicas estão sendo realizadas e pesquisas são constantemente desenvolvidas. Dentre as principais podemos citar o controle químico, fitoterápico, homeopático e observações de condições de ambiência, mas até o momento todos tem demonstrado eficiência parcial.

Palavras-chave: Estresse por calor, Bos taurus, Rhipicephalus microplus. 


\title{
The influence of co-evolution cattle/ticks in control methods and ambience the cattle
}

\begin{abstract}
The cattle is very developed in Brazil, but ectoparasites, especially ticks, increase the cost of production and hamper the activity. In Brazil cattle are exotic, when imported they also brought their parasites. For mite control several techniques are being implemented and research is constantly developed. Among the main control principles chemical control, herbal, homeopathic and observations of conditions ambience, but so far all have demonstrated partial efficiency.
\end{abstract}

Keywords: Heat stress, Bos taurus, Rhipicephalus microplus.

\section{INTRODUÇÃO}

A pecuária bovina brasileira é uma atividade que abastece o consumo interno e ainda exporta excedente gerando divisas para o país. O Ministério da Agricultura, Pecuária e Abastecimento (MAPA) projeta os dados da bovinocultura até 2020 para a produção e consumo de leite (Tabela 01), onde a produção é menor que o consumo, obrigando o país a importar lácteos. A produção de carne (Tabela 02) demonstra autossuficiência e excedentes, com essas informações disponíveis pode-se tomar decisões no campo político e produtivo, mas também demonstram quanto é necessário um incremento de produção, dessa importante fonte de alimentos e renda, pois há necessidade deste excedente para gerar divisas ao país.

Tanto a produção de leite quanto a produção de carne enfrentam desafios que devem ser encarados e vencidos nos próximos anos, tais como: falta de organização das cadeias produtivas de carne, de forma muito peculiar a do leite onde cada elo vê no seguinte ou no anterior um adversário e não um parceiro. A qualidade da produção nacional ainda considerada ruim devido à presença de doenças, principalmente zoonoses. A falta de cuidado na criação, produção, transporte de animais, de carnes, leite e derivados, onde muitas 
vezes há a necessidade de interferência dos órgãos de saúde pública para se evitar produção, comercialização e consumo de carne ou leite deteriorado. A sazonalidade da produção, pois as áreas produtoras encontram-se em região com dois climas bem definidos, sendo nas águas excesso de produção e na seca escassez, com baixa produção e até morte de animais. Falta de tecnologia adaptada a esta sazonalidade, uma vez que há a tendência de se importar técnicas desenvolvidas em regiões de condições ambientais diferentes daquelas existentes no Brasil. Contudo o país é o grande produtor de carne e leite a pasto, evitando o confinamento total dos animais, produzindo o chamado "boi verde".

Tabela 01 - Projeções de produção e consumo de leite de vacas pelo MAPA no período 2011/2020, em milhões de litros/ano.

\begin{tabular}{lllllllllll}
\hline & $\mathbf{2 0 1 1}$ & $\mathbf{2 0 1 2}$ & $\mathbf{2 0 1 3}$ & $\mathbf{2 0 1 4}$ & $\mathbf{2 0 1 5}$ & $\mathbf{2 0 1 6}$ & $\mathbf{2 0 1 7}$ & $\mathbf{2 0 1 8}$ & $\mathbf{2 0 1 9}$ & $\mathbf{2 0 2 0}$ \\
\hline Prod. & 32.539 & 33.261 & 33.950 & 34.620 & 35.285 & 35.947 & 36.608 & 37.268 & 37.929 & 38.589 \\
Cons. & 33.413 & 34.149 & 36.092 & 35.510 & 36.183 & 36.855 & 37.526 & 38.197 & 38.867 & 40.208 \\
\hline
\end{tabular}

FONTE: MAPA 2012.

Tabela 02 - Projeções de produção e consumo de carne bovina pelo MAPA no período 2011/2020, em mil toneladas/ano.

\begin{tabular}{lllllllllll}
\hline & $\mathbf{2 0 1 1}$ & $\mathbf{2 0 1 2}$ & $\mathbf{2 0 1 3}$ & $\mathbf{2 0 1 4}$ & $\mathbf{2 0 1 5}$ & $\mathbf{2 0 1 6}$ & $\mathbf{2 0 1 7}$ & $\mathbf{2 0 1 8}$ & $\mathbf{2 0 1 9}$ & $\mathbf{2 0 2 0}$ \\
\hline Prod. & 8.947 & 9.973 & 10.523 & 10.714 & 11.202 & 11.338 & 11.143 & 11.203 & 11.457 & 11.551 \\
Cons. & 7.423 & 8.113 & 8.386 & 8.306 & 8.534 & 8.751 & 8.687 & 8.804 & 9.163 & 9.332 \\
\hline
\end{tabular}

FONTE: MAPA 2012.

Os animais são sujeitos a parasitismos e aqueles de alta produção principalmente de leite não estão adaptados ao clima tropical. A adaptação desses animais ao clima tropical ou subtropical é uma grande busca tecnológica, genética e de ambiência, principalmente pela origem dos animais uma vez que são exóticos à nossa falta. Sem a devida adaptação não 
conseguem para expressarem suas características genéticas para produção tornando a pecuária pouco lucrativa.

O parasitismo é uma relação ecológica danosa a uma das espécies, que se define como a relação em que uma espécie retira o seu alimento de outra espécie prejudicando-a, podendo levar a espécie hospedeira à morte, mas o intuito do parasito não é este, pois se o hospedeiro morre geralmente o parasito também. Visando melhores condições para conseguir seu sustento com menor esforço o parasito desenvolve constantemente melhores armas, seja através de um aparelho bucal mais eficiente, mais cortante, seja com a produção de enzimas que burlam o sistema de defesa do hospedeiro e o hospedeiro por sua vez também evolui seu sistema de defesa, buscando livrarse da espoliação que o parasito me impõe. É uma corrida armamentista, parasitas evoluindo para escapar do sistema imune hospedeiro e hospedeiros evoluindo para eliminar os parasitas através de seu sistema imune (HONGO, NETO e LOBO, 2012).

No Brasil a área de criação se concentra entre o trópico de Capricórnio e - Equador, fazendo com que seja uma área de em que há uma grande quantidade de luz solar, calor, presença de ectoparasitos e principalmente do carrapato bovino (Rhipicephalus microplus). A presença desse ectoparasito e as tentativas de exterminá-lo são elementos dessa corrida armamentista desde os primeiros relatos de sua existência em solo brasileiro. Com a necessidade de produção cada vez maior de leite e carne os produtores lançam mão de várias técnicas de controle, mas nenhuma até o momento tem sido eficiente o suficiente, mostrando que o carrapato tem burlado técnicas e medicamentos, além de apresentar uma alta capacidade de adaptação e de desenvolver resistência a acaricidas (FURLONG e PRATA, 2004).

O carrapato além de esfoliar os bovinos pode transmitir inúmeras doenças aos bovinos, aos outros animais e ao homem. Doenças como a "tristeza parasitária", que é provocada por Rickettsia, anaplasma e/ou Babesia spp são doenças que provocam grandes danos na pecuária leiteira e tem o carrapato como vetor, além destas, outras doenças como as arboviroses, 
richetsioses, espiroquetoses e outras causadas por protozoários também são transmitidas ao homem e aos animais domésticos pelo carrapato (KAUFMAN, 1989).

Buscou-se fazer um levantamento bibliográfico sobre a evolução das espécies Bos taurus, e suas subespécies e o seu principal ectoparasita o Rhipicephalus microplus, com os métodos de controle do parasito e a influência da ambiência animal nessa relação ecológica.

\section{REVISÃO DE LITERATURA}

\section{História Evolutiva do Bovino (Bos taurus, Bos indicus)}

Os bovinos são animais pertencentes ao Filo Chordata, subfilo Vertebrata, Classe Mammália, Ordem Artiodactyla, Família Bovidae, Subfamília Bovinae, Gênero Bos, espécie taurus e sub espécies taurus e indicus

Segundo Gasparin (2007) a divisão mais usual é a de Bos taurus e Bos indicus (Lineau, 1778), como duas espécies distintas, contraria o conceito de espécie, pois espécies diferentes não geram descendentes férteis e não é isso o que acontece entre os bovinos, confirmando pesquisas de Hansen (2004), através de análise do DNA mitocondrial e o uso de marcadores microssatélites indicam que Bos indicus deriva do Bos taurus, sendo correto afirmar que a espécie é Bos taurus que é composta por duas subespécies a Bos taurus taurus e Bos taurus indicus.

É hoje aceito pela maioria dos investigadores que a formação da espécie bovina ocorreu na Ásia Menor e que partiu para os vários pontos do globo, seguindo duas formas e em épocas substancialmente diferentes. Primeiro irradiou, à medida que ocorria o degelo, sob a forma selvagem e, depois, já no decurso dos grandes movimentos migratórios do Homem após o neolítico, sob a forma de animal doméstico.

A primeira forma da espécie bovina foi designada por Bos taurus primigenius, que segundo a descrição de GARCÍA-FIERRO (1956, apud ALVES 2004), era um animal de grande porte (os machos mediam, de altura à 
cernelha, de 1,8 a 2 metros e as fêmeas de 1,5 a 1,7 metros) e de cor negra ou castanha escura (ALVES, 2004).

Estudos arqueológicos demonstram que os bovinos atuais são descendentes do auroque (Bos primigenius), com exceção do gado de Bali e de Mithan, extintos a mais de 2000 anos da sua região de origem (EPSTEIN e MASON1984, apud CERVINI, 2009). Os animais pertenciam a 3 raças continentais, sendo a Bos primigenius namadicus que povoavam a Ásia, Bos primigenius opisthonomous na África e Bos primigenius primigeniusna Europa, que foram domesticados em eventos diferentes, supondo-se pelos informes fósseis que a primeira domesticação ocorreu na Europa em busca de facilitar a obtenção de alimento e posteriormente de trabalho. Já na Ásia, mais especificamente na Índia a busca por auxiliares no trabalho dos humanos foi o mote da domesticação (CERVINI, 2009).

\section{Bovinos no Brasil}

Nas primeiras décadas após o descobrimento, bovinos de origem europeia foram introduzidos no Brasil pelos colonizadores. Com a adaptação e a mistura de raças de origens diversas trazidas durante a colonização, surgiram as diferentes raças brasileiras, dentre elas, o Curraleiro (Pé-duro), o Franqueiro ou Junqueiro, o Caracu, o Mocho Nacional, o Crioulo Lageano e o Pantaneiro . No início do século XIX iniciaram-se as importações de gado Zebu, importado em maior escala mais tarde, primeiramente como fonte de energia para os transportes da época. Mas foi no início do século XX que houve, provavelmente, a introdução definitiva do Zebu indiano no Brasil (EUCLIDES FILHO \& FIGUEIREDO, 2003). Em 1963, houve a última grande importação de germoplasma da Índia (FERRAZ, 2003).

\section{História Evolutiva do Carrapato (Rhipicephalus microplus)}

O carrapato do boi (Rhipicephalus microplus) é um ácaro que foi descrito pela primeira vez em uma tumba do antigo Egito em 1.500 A.C.. A maioria dos carrapatos que parasitam os bovinos é da espécie Rhipicephalus microplus, 
pertencente ao Filo Arthropoda, Subfilo Chelicerata, Classe Aracnida, Subclasse Acari, Ordem Parasitiforme, Subordem Ixodides, Família Ixodidae e Gênero Boophilus (FURLONG 2005).

Como a evolução das espécies aconteceu no planeta ainda tem pontos a serem esclarecidas principalmente as co evoluções, segundo FRANZIN (2009) a evolução do carrapato tem vários explicações, aquelas mais aceitas, afirmam que são vários os caminhos evolutivos que levaram as 15000 espécies de artrópodes divididos em mais de 400 gêneros se tornarem hematófagos. As primeiras evidências de artrópodes hematófagos são datadas do final do período Cretáceo (145 a 65 milhões de anos atrás). O seu surgimento no período Devoniano (417 a 362 milhões de anos) não é descartado, esse período geológico é o mesmo do surgimento dos anfíbios.

Para a aceitação da coevolução é necessário que se encontre vestígios fósseis das espécies que se quer estudar próximos uns dos outros como o carrapato tem a maioria de suas estruturas físicas degradam com facilidade, pois não possuem esqueleto ósseo, essa relação é de difícil comprovação, alguns autores postulam que se desenvolveram como parasitas obrigatórios de répteis no final do período paleolítico ou início do mesolítico, em climas quentes e úmidos. Supõe-se que quando esses répteis se ramificaram em numerosas formas de vida, preenchendo nichos aquáticos e terrestres, seus carrapatos mais primitivos evoluíram em duas principais famílias, Argasidae e Ixodidae. A espécie R.microplus originou-se provavelmente da Ásia, quando mamíferos e pássaros substituíram os répteis como vertebrados dominantes, já no período terciário (ROCHA, 2003).

Outros afirmam que parasitismo dos artrópodes é justificado pela teoria segundo a qual a coabitação em tocas e ninhos por artrópodes, répteis, aves e mamíferos nos períodos Jurássico e/ou Cretáceo (250 a 65 milhões de anos) pode ser o início para a hematofagia. Os artrópodes pela proximidade com os vertebrados inicialmente lambiam suas feridas e escamações de pele, com a mudança de habitat dos vertebrados os parasitos desenvolveram seu aparelho 
bucal para cortarem e até mesmo perfurarem a pele dos hospedeiros (FRANZIN, 2009).

Apesar das incertezas sobre a origem do Rhipicephalus microplus no planeta é correto afirmar que a existência desse organismo nas Américas é recente, pois como não havia bovinos no continente não havia este parasito. Acredita-se que a presença do carrapato ocorreu pela introdução de forma descuidada dos hospedeiros vindos das ilhas portuguesas e da África inicialmente, uma vez que a chegada dos Bos indicus nas Américas é mais recente.

O carrapato tem como maior adversário para sua sobrevivência as condições climáticas sendo muito sensível para baixas temperaturas, à presença desse ectoparasito é relatada em todos os rebanhos bovinos comerciais das Américas, África, Ásia e Oceania entre os paralelos $32^{\circ}$ norte e $32 \circ$ sul (FURLONG e PRATA, 2004).

O R. microplus desenvolveu durante sua evolução uma estratégia de sobrevivência com um ciclo de vida em duas fases distintas, sendo uma fase de vida parasitária e uma fase de vida livre. A fase de vida parasitária é dividida em: larva infectante (também conhecida como micuim), ninfa e adulto. Nos adultos há dimorfismo sexual, o macho é menor que a fêmea e não se alimenta de sangue ao contrário da fêmea, que é hematófaga. A fêmea ingurgitada ou teleógina é aquela cheia de sangue. Após se ingurgitar a fêmea desprende-se do hospedeiro, uma vez no solo faz a ovopostura, dando início à fase de vida livre.

Durante a fase de vida livre a teleógina, logo após o seu desprendimento do hospedeiro, dá início à postura depositando ovos no solo (em média 3.000 ovos) e morre em seguida. Os ovos ficam incubados no solo aguardando situação ideal para eclodirem, condições ambientais como: temperatura, umidade e outras. Após a eclosão dos ovos, estes evoluem para a fase de larva que sofrem metamorfose e se transformam em larva infectante, permanecendo na vegetação até o surgimento de um hospedeiro e assim recomeçar a fase de vida parasitária. 
Um grande problema para a erradicação do carrapato é o seu próprio ciclo de vida, pois para cada carrapato encontrado na fase parasitária, há aproximadamente noventa e nove na fase de vida livre (FURLONG, 2005).

\section{Métodos de controle do carrapato}

O rebanho brasileiro comercial é a somatória do cruzamento de animais europeus e indianos, onde os animais de origem europeia são mais precoces, pesados e produtores de leite e carne, com os de origem indiana são mais rústicos, mais resistência aos ectoparasitas. O $R$. microplus demonstra maior infestações nos animais Bos taurus, por que o $B$. Indicus co-evolui com o carrapato e criou maiores barreiras ao ectoparasito, quer por tipo de pelo e pele, quer por alterações nos sistema imune. Os cruzamentos com animais com maior porcentagem de gens Bos taurus e o surgimento de novas variedades e espécies de gramíneas para pastejo (Brachiaria spp e Pennisetun $\mathrm{spp)}$ permitem maior lotação por área, favorecem o favorecimento a multiplicação, sobrevivência e desenvolvimento do carrapato (FURLONG,1992).

\section{Controle com acaricidas}

Desde o final do século XIX, há uma busca constante de produtos para se de combater o carrapato dos bovinos (Rhipicephalus microplus). Foram usadas várias substâncias como: creosoto, sabão, fumo, querosene e enxofre, sempre, porém, adicionados a óleos minerais. Não alcançando sucesso, inclusive levando os bovinos à morte por intoxicação.

Em 1896 surgiu a solução, por meio de um fazendeiro australiano, o qual formulou uma receita de sucesso baseada no uso do arsênico em diluição na água e para utilização em banho, a qual foi instituída como oficial pelo governo da Austrália, mas provocou à seleção artificial de populações, essa seleção é chamada de resistência.

No Brasil, populações resistentes ao arsênico começaram também a aparecer em 1946, e foram controladas com BHC, DDT e outros produtos do grupo químico dos organoclorados. 
Desde esse período, a preocupação com o controle do carrapato dos bovinos cresceu consideravelmente no país. Apesar da preocupação, dos investimentos realizados e pesquisas o acaro esta sendo capaz de desenvolver estratégias de defesa contra os acaricidas utilizados, levando a uma constante busca por novas moléculas e dosagens disseminando a resistência entre as populações de carrapatos no Brasil (FURLONG, et al., 2007).

Os grupos de acaricidas mais utilizados, segundo Andreotti (2010) são divididos em:

- Organofosforados: grupo mais antigo de carrapaticida ainda comercializado para bovinos. Apareceram em torno de 1955 para substituir os organoclorados.

- Amidinas (diamínicos): grupo de carrapaticidas que sucedeu aos fosforados sendo lançado em 1975. Caracteriza-se por ter poder residual de 14 dias, permitindo intervalos maiores de tratamentos. Após penetrar no carrapato, a amidina é metabolizada em um composto denominado de $\mathrm{N}-2,4$ - dimetilfenil $\mathrm{N}$ - metilformamidina.

- Piretroides: surgiu em 1977. Com o aparecimento de resistência aos acaricidas de grupos à base de organofosforados tradicionalmente usados no país na década de 1980, foi estimulado o uso extensivo de piretrôides. Existem no mercado produtos originários de pelo menos três subgrupos dessa família (Deltametrina, Cipermetrina e Alfametrina).

- Fipronil: sua ação é semelhante às avermectinas, isto é, age sobre o sistema nervoso dos carrapatos, paralisando-os. Ainda não existe relato de resistência do R. microplus ao fipronil. Não pode ser usado em animais em lactação e é aplicado de forma "pour on".

- Thiazolina: possui formulação em associação com piretroide, e é utilizado na forma de pulverização ou imersão. Liberado para uso em animais em lactação, tem carência de apenas três dias para a utilização da carne. Ainda não existe relato de resistência do R. microplus à thiazolina. 
- Lactonas macrocíclicas: esses produtos surgiram no início da década de 1980 (1981) e produziram grande revolução no mercado mundial dos antiparasitários. Além de apresentarem maior poder residual que os piretroides, são também eficientes contra vermes e bernes, sendo por isso chamados de "endectocidas". São derivados de produtos obtidos com a fermentação do fungo Streptomyces avermitiles, e existem quatro subgrupos no mercado (Ivermectin, Moxidectin, Doramectin e Abamectin) (FURLONG; MARTINS, 2000).

- Fluazuron (inibidor do crescimento): o fluazuron tem a capacidade de interferir na produção de quitina, uma substância que possibilita o endurecimento da cutícula dos carrapatos. Completamente diferente de todos os carrapaticidas já citados, ele não permite que os carrapatos mudem de fase e cresçam, além de impedir que se reproduzam, controlando a população. De maneira semelhante aos derivados das avermectinas, também não pode ser utilizado nos animais em lactação (ANDREOTI, 2010).

\section{Controle biológico}

O controle biológico tem utilizado animais que demonstrem maior resistência ao ácaro, cultivo de pastagens que dificultem a sobrevivência dos estágios vida livre do ácaro. Preservação de predadores naturais como: a garça boiadeira (Egretta íbis), gaviões tais como o carcará (Polyborus plancus) e o gavião-carrapateiro (Milvago chimachima), formigas e vespas predadoras. A utilização de bactérias, fungos e nematódeos também estão sendo testados e pesquisados (LEAL, ET AL, 2003).

\section{Vacinas}

Recentemente pesquisa que buscam métodos de controle através de vacinação do hospedeiro tem seu desenvolvimento, mas ainda sem a eficácia desejada. A inoculação no hospedeiro moléculas ou enzimas produzidas pelo parasito, visando estimular a defesa contra o hospedeiro (ANDREOTTI, et al., 
2002). O desenvolvimento de vacinas basea-se atualmente na teoria de "anticorpos ocultos", que são aqueles não detectados pelo sistema imune dos hospedeiros, atualmente temos duas vacinas que utilizam a proteína Bm 86, uma desenvolvida na Austrália, que é a TickGard e outra a Gavec desenvolvida em Cuba, mas não dispensa a utilização de acaricidas. A busca por antígenos mais eficientes, proteínas e outras moléculas que possam controlar os ectoparasitas tem sido o mote de inúmeras pesquisas (LEAL, ET AL, 2003).

\section{Fito terapia}

Nesse contexto, a fitoterapia é considerada uma alternativa importante no controle de parasitas, podendo reduzir os impactos econômicos e ambientais ao uso de pesticidas sintéticos, mas a variabilidade de espécies de plantas, pesquisas sobre seu uso no controle de parasitas de animais são escassas, havendo carência de informações complementares em relação às condições de produção, à época de colheita e às quantidades e partes da planta utilizadas na elaboração dos antiparasitários (HEIMERDINGER, 2006). A utilização de várias plantas como: a citronela (Cymbopogon nardus L. Rendle), cultivada em regiões tropicais e subtropicais. O óleo extraído de suas folhas, frescas ou parcialmente dessecadas, é usado como repelente de mosquitos. estudos feitos com destilados de folhas de citronela demonstraram elevada ação carrapaticida, tanto em larvas quanto em fêmeas adultas, sendo usados, no entanto, óleo puro e níveis considerados altos de óleo em etanol, de 1:4. Essa propriedade é atribuída à presença de substâncias voláteis em suas folhas, como citronelal, eugenol, geramiol e limoneno, entre outras, denominadas de um modo geral como monoterpenos (OLIVO, 2008), óleo de e andiroba (Carapa guianensis) também é utilizado, fumo de corda (FARIAS, et al.,2007), Cymbopogon citratus (capim santo), Lippia alba (erva cidreira), Ipomoea asarifolia (salsa) e o Azadirachta indica (óleo de nim a 1\%) (SILVA, et al.,2008), entre outros. 


\section{Controle homeopático}

Souza (2002) relata que existem proprietários que utilizam os bioterápicos em bovinos, caninos, caprinos e outros, desde a década de 70 com sucesso no controle de ectoparasitos. Observa-se nestes tratamentos que não há o extermínio dos parasitos, e sim uma infestação insignificante nos animais hospedeiros, que não causa prejuízo à saúde destes, bem como traz vantagens financeiras aos proprietários. Os produtos dos animais tratados, como o leite e a carne não apresentam resíduos tóxicos, especialmente o leite que exibe uma melhora na sua qualidade (ARENALES, 2002; MENDONÇA, 2000).

\section{Influência da Ambiência no controle do carrapato do boi}

O Brasil como país continental e com sua área localizada praticamente entre o paralelo $32^{\circ} \mathrm{S}$ e a linha do equador enfrenta na sua pecuária o desafio de proporcionar aos animais de produção uma ambiência que Ihes propicie a expressão de suas características genéticas produtivas, mas o custo dessa ambiência muitas vezes inviabiliza a produção se for observado apenas o enfrentamento sem lançar mão de estratégias que contornem o desconforto térmico e principalmente as condições climáticas favoráveis ao $R$. microplus, para tanto cuidados como: seleção de animais mais adaptados, mesmo dentro de raças europeias (ALENCAR e BARBOSA, 2009). Buscar técnicas de manejo tanto de animais como de pastagens, procurando o rotacionar os animais nas pastagens (FURLONG, 2007), e utilização de produtos que auxiliem no controle desse ectoparasitas, pois a sua extinção não seria viável e até indesejável, uma vez que a baixa infestação propicia ao hospedeiro a estimulação do seu sistema imune, desenvolvendo anticorpos para doenças que é vetor (ANDREOTTI, ET AL，2002; ARENALES， 2002; CERVINI， 2009; FURLONG, 2005) 
MORAIS, P.G.S. et al. A influência da co-evolução bovinos/carrapatos nos métodos de controle e ambiência na bovinocultura. PUBVET, Londrina, V. 7, N. 9, Ed. 232, Art. 1534, Maio, 2013.

\section{CONCLUSÃO}

A produção bovina brasileira apesar dos empecilhos principalmente pela pouca adaptação de animais europeus tem buscado soluções para produzir mais e melhor, levando em conta as pesquisas, às relações ecológicas e a ambiência do bovino.

\section{REFERÊNCIAS}

ALENCAR, M. M.; BARBOSA, P. F. Melhoramento Genético de Gado de Corte no Brasil. Boletim Embrapa Pecuária Sudeste, 2009.

ALVES, V. Evolução Filogenética dos Bovinos Autóctones Portugueses. Anais: II Jornadas Técnicas de Raças Bovinas Autóctones. Escola Superior Agrária - Castelo Branco. 2004.

ANDREOTTI, R. Situação atual da resistência do carrapato-do-boi Rhipicephalus (Boophilus) microplus aos acaricidas no Brasil. Campo Grande, MS. Embrapa Gado de Corte. 36 p. 2010.

ANDREOTTI, R.; ALBERTO GOMES, A.; MALAVAZI-PIZA K. C.; TANAKA, A. S. Controle do carrapato por meio de vacina - situação atual e perspectivas. Campo Grande. Embrapa Gado de Corte, 58 p. 2002.

ARENALES, M. C., - E. N. Complementary control of ticks (Boophilus) microplus) in dairy cattle (Bos taurus) -holstein with the administration of the C\&MC factor, (homeopathic product) Brasil. Hannover: Alemanha. 2002.2 Disponível em: <http://www.arenales.com.br/trabalho_03.asp>.

BRASIL. MINISTÉRIO DA AGRICULTURA, PECUÁRIA E ABASTECIMENTO. Projeções do Agronegócio : Brasil 2011/2012 a 2021/2022. Ministério da Agricultura, Pecuária e Abastecimento. Assessoria de Gestão Estratégica. Brasília : Mapa/ACS, 2012.

CERVINI, M. Mapeamento de QTL nos Cromossomos 24 e29 para Medidas de Peso, Resistência a Carrapato e Estresse Térmico em uma População $F_{2}$ (Gir x Holandez). UFSCar. São CarlosSP. 86 p. 2009. Disponível em: http://www.bdtd.ufscar.br/htdocs/tedeSimplificado, acesso em: $27 / 11 / 2012$, Às $11,01 \mathrm{~h}$.

EUCLIDES FILHO, K.; FIGUEIREDO, G.R. Retrospectiva e perspectivas de cruzamentos no Brasil. In: SIMPÓSIO BRASILEIRO SOBRE CRUZAMENTO DE BOVINOS DE CORTE, 1., 2003, Londrina, PR. Disponível em: http://www2.ufersa.edu.br, acesso às 19/10/2012, às 19,10 h.

FARIAS, M.P.O.; SOUSA, D.P.; ARRUDA, A.C.; ARRUDA, M.S.P.; WANDERLEY, A.G.; ALVES, L.C.; FAUSTINO, M.A.G. Eficácia in Vitro do Óleo da Carapa guianensis Aubl. (andiroba) no controle de Boophilus microplus (Acari: Ixodidae). Rev. Brasileira. Pl. Medicina, Botucatu, v.9, n.4, p.68-71, 2007.

FERRAZ, J. B. S. Programas de avaliação genética de bovinos de corte no Brasil. In: WORKSHOP SOBRE INTEGRAÇÃO DE DADOS DE AVALIAÇÕES GENÉTICAS DE BOVINOS DE CORTE, 1., 2003, Pirassununga, SP. Disponível em: http://www.sbmaonline.org.br/, acesso em $18 / 10 / 2012$, às $23,30 \mathrm{~h}$. 
FRANZIN A. M. Imunologia das infecções de bovinos pelo carrapato Rhipicephalus (Boophilus) microplus: estudo dos correlatos imunes de resistência e susceptibilidade. Faculdade de Medicina de Ribeirão Preto/Universidade de São Paulo. Ribeirão Preto 2009134 p (Tese de Doutorado). Disponível em: www.teses.usp.br/teses/disponiveis/17/17147, acesso em $20 / 10 / 2012$, às $19,35 \mathrm{~h}$.

FURLONG, J. Carrapato - problemas e soluções. Juiz de Fora - MG. Embrapa Gado de Leite. 2005.

FURLONG, J.; MARTINS, J. R.; PRATA, M .C. A. O Carrapato dos Bovinos e a Resistência: Temos o que Comemorar? A Hora Veterinária - Ano 27, no 159. 2007. Disponível em: http://cpamt.sede.embrapa.br/biblioteca, acesso em 20/10/2012, às 10,30 h.

FURLONG, J.; MARTINS, J. R. S. Resistência dos carrapatos aos carrapaticidas. Juiz de Fora, MG: Embrapa Gado de Leite. 25 p. 2000.

FURLONG, J.; PRATA, M. Instrução técnica para o produtor de leite - Resistência dos carrapatos aos carrapaticidas. Juiz de Fora - MG. Embrapa Gado de Leite - 2004.

GUSTAVO, G. Mapeamento de QLT para Resistência a Parasitas e Características de Crescimento nos Cromossomos Cinco e Sete de uma População Experimental F2 de Bovinos Gir $x$ Holandês. São Carlos. UFSCar. 87 p. 2007. Disponível em: www.bdtd.ufscar.br/htdocs/tedeSimplificado, acesso em 10/10/2012, às 9,30 h.

HANSEN, P. J. Physiological and cellular adaptations of zebu cattle to thermal stress. Animal Reproduction Science. v.2, p.349-360, 2004.

HEIMERDINGER, A. Extrato alcoólico de capim-cidreira no controle do Boophilus microplus em bovinos. Revista Brasileira de Parasitologia Veterinária, v.15, n.1, p.37-39, 2006.

HONGO, J. A.; NETO, A. Z.; LOBO, F. P. Detecção e Análise Bioinformática de Genes Sob Evidência de Seleção Positiva em Genomas de Parasitos. Anais: $6^{\circ}$ Congresso de Interinstitucional de Iniciação Científica - CHC 2012. Jaguariúna-SP. Agos 2012. www.cnpma.embrapa.br/eventos/2012, acesso em 20/10/2012, às 19,45 h.

JOAZEIRO, A. C.; COUTINHO, M. L.; MARTINS, J. R.; MASUDA, A.; SEIXAS, A. VAZ JUNIOR, I S. Peptídeos antimicrobianos em Rhipicephalus (Boophilus) microplus. Acta Scientiae Veterinariae. 40(4): 1066. Porto Alegre-RS. 2012. Disponível em: http://www.ufrgs.br/actavet, aceso em 22/10/2012, às 19,50 h.

KAUFMAN, W. R. Tick-host interaction: a synthesis of current concepts. Parasitol Today 1989.

LEAL, A. T. F. ; FREITAS, D. R. J.; VAZ JUNIOR, I. S. Perspectivas Para o Controle do Carrapato Bovino. Acta scientiae veterinariae. Porto Alegre, RS. Vol. 31, n. 1. 2003, p. 1-11.

MENDONÇA, A. Homeopatizadas com o Fator M\&P e Propriedades Não Homeopatizadas da Bacia Leiteira da Região de Erechim/RS, de Fevereiro a Maio de 2.000. Campinas do Sul - RS. 2000.

OLIVO, C. J.; CARVALHO, N. M.; SILVA, J. H. S.; VOGEL, F. F.; MASSARIOL, P.; MEINERZ, G.; AGNOLIN, C.; MOREL, A. F.; VIAU, L. V. Óleo de Citronela no Controle do Carrapato de Bovinos. Ciência Rural, v.38, n.2, 2008. 
ROCHA, C. M. B. M. Aspectos Relevantes da Biologia do Boophilus microplus (Cannestrini, 1887). Boletim da Universidade Federal de Lavras, 2003 - editora.ufla. br. Disponível em www.editora.ufla.br, acesso em 22/10/2012, às 20,45 h.

SANTOS JÚNIOR, J. C.B.; FURLONG, J.; DAEMON, E. Controle Do Carrapato Boophilus Microplus (Acari: Ixodidae) em Sistemas de Produção de Leite da Microrregião Fisiográfica Fluminense do Grande Rio - Rio De Janeiro. Ciência Rural, Santa Maria, v. 30, n. 2, p. 305$311,2000$.

SILVA, F. F.; SOARES, M. C. S. C.; ALVES, L. C.; LIMA, M. M.; SILVA, L. V. A.; FAUSTINO M. A. G.; SILVA JÚNIOR, F. F. Avaliação comparativa da eficácia de fitoterápicos e produtos químicos carrapaticidas no controle do Boophilus microplus (Canestrini, 1887) por meio do biocarrapaticidogramas. Medicina Veterinária, Recife, v.2, n.3, p.1-8, 2008.

SOUZA, M. F. A. Homeopatia Veterinária. In: I Conferência Virtual Global sobre Produção Orgânica de Bovinos de Corte, 2002. 